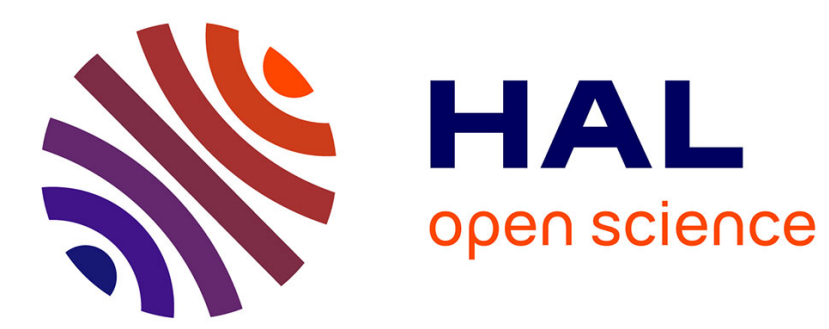

\title{
Mapping Patterns of Co-innovation Networks
}

\author{
Paula Urze, António Abreu
}

\section{To cite this version:}

Paula Urze, António Abreu. Mapping Patterns of Co-innovation Networks. 17th Working Conference on Virtual Enterprises (PRO-VE), Oct 2016, Porto, Portugal. pp.241-252, 10.1007/978-3-319-453903_21. hal-01614587

\section{HAL Id: hal-01614587 https://hal.inria.fr/hal-01614587}

Submitted on 11 Oct 2017

HAL is a multi-disciplinary open access archive for the deposit and dissemination of scientific research documents, whether they are published or not. The documents may come from teaching and research institutions in France or abroad, or from public or private research centers.
L'archive ouverte pluridisciplinaire HAL, est destinée au dépôt et à la diffusion de documents scientifiques de niveau recherche, publiés ou non, émanant des établissements d'enseignement et de recherche français ou étrangers, des laboratoires publics ou privés. 


\title{
Mapping Patterns of Co-innovation Networks
}

\author{
Paula Urze1 (pcu@fct.unl.pt), António Abreu² (ajfa@dem.isel.ipl.pt) \\ ${ }^{1}$ FCT/UNL - Faculdade de Ciências e Tecnologia, Universidade Nova de Lisboa, Portugal \\ ${ }^{2}$ ISEL- Instituto Superior de Engenharia de Lisboa, Instituto Politécnico de Lisboa \\ ${ }^{2}$ CTS - Uninova, Faculdade de Ciências e Tecnologia, Universidade Nova de Lisboa, Portugal
}

\begin{abstract}
In recent decades a significant research effort has focused on the role of innovation in giving enterprises a competitive advantage, and of socioeconomic growth in general. Using the debate about systems as frameworks for innovation and the mapping of stages of innovation as our starting point, this paper aims to introduce an approach to understand the role of different types of co-innovation networks in terms of their capacity to generate novelty in terms of processes and products. The paper's empirical section is based on one case study about Portugal's largest highway concessionaire.
\end{abstract}

Keywords: collaborative networks, innovation, types of co-innovation networks

\section{Introduction}

In recent decades a significant research effort has focused on the role of innovation in giving enterprises a competitive advantage, and of socio-economic growth in general. There is also a growing stream of literature analyzing models of innovation. [1] [2] Different perspectives have emerged associated to an effort to explain the social and institutional conditions of competitiveness in a collaborative environment such as industrial districts, industrial clusters, virtual organizations and collaborative innovation networks. [3]. Recent research in socio-economic issues has also pointed out the role of networking as an element, which facilitates communication, thereby promoting increased information dissemination and knowledge sharing. One can detect a convergence of opinions from different schools of thought when attempting to study the factors that contribute to improving an innovative performance among enterprises and sectors. [4]. Furthermore, a number of contributions on this same subject can be found in innovation literature.

In fact, cooperating and networking are essential assets in the search for an innovative growth path. Nonetheless, enterprises gain the crucial competitive advantage through the ability to coordinate resources and deploy them effectively, considering knowledge as a key cornerstone for innovation and making sure it ranks first in the hierarchy of the organization's strategically relevant resources [5].

Networking may open the possibility, not only for the sharing of knowledge, but also for the launching of the knowledge-creation process itself. This may enable enterprises to strengthen their technological and innovative competencies. Within this assumption, the main purpose of this paper is to develop an approach for understanding the role of different types of co-innovation networks in terms of their capacity for generating new ideas, processes or services. 


\section{A Systemic Perspective of Innovation}

Currently, there is a broad consensus among scholars of innovation that a systemic approach to innovation activities provides a more complete representation of reality, as opposed to the linear model. The systemic approach takes into account the need for a broader perspective of the innovation process, putting it within the framework of an innovation system. [6]. The systemic perspective consists of a structure formed by a set of interdependent organizations in an institutional context, shaping the way systems work and determining the action of the systems.

The concept of innovation has been submitted to transformations over time, along with the development of models that attempt to understand the process. At first, it was thought that innovation was the result of a linear and hierarchical process, which starts with basic research, successfully going through consecutive stages, from applied research and development to production and marketing. Public intervention has a greater presence and intensity at the higher levels such as in universities and other public organizations, and it is more moderate, or does not take place at all, in the lower levels such as production and marketing. [7,8].

Contrasting with the 'linear model', the 'chain linked model' [9] developed in the 1980 s considers that the innovation process takes place through a series of interactions and interdependencies. These occur within enterprises, between them and also through upstream activities, e.g. scientific and technological organizations, suppliers of goods, services, equipment and technology and in the downstream, e.g. distribution, industrial customers and end users. Moreover, the process is not hierarchical because innovative impulses can originate either from new scientific insights and technology or at the market level. Under this model, public intervention is different from the 'linear model'. The 'chain linked model' becomes less differentiated from one stage to another and does not contain the formal distinction between enterprises and other stakeholders. [10]

The innovation process is influenced by several factors. Due to this complexity, enterprises rarely innovate alone. The innovation path interacts with other organizations to gain, develop and exchange different forms of knowledge, information and other resources. These may be other enterprises, suppliers, customers and competitors or also universities and research institutes. [11] Through their innovation activities, enterprises establish relationships among themselves and with other organizations. However, it makes sense to look for isolated innovative enterprises and individual decision-making units. Enterprise behavior is also shaped by institutions that constitute constraints or incentives for innovation, such as laws, cultural norms, social rules and technical standards. The interaction between various organizations operating in different institutional settings is important for the innovation process. The actors as well as the context factors are all important elements in the creation and use of knowledge for economic purposes. [12,13] As a result innovation in such systems can emerge. 


\section{Stages for Mapping Innovation}

As regards technological innovation, it is important to stress that one of the main concerns of enterprises is to measure the technological maturity of a new technology and capability (engineering or economic performance). Thus, the Technology Readiness Level (TRL) scale, developed in the 1970s and 80s by NASA, has been largely used by different sectors and has often been adapted to the specific needs of organizations. [14]

The initial scale contained 7 levels and has now been expanded to a 9-level scale that has broad acceptance through industry and public organizations. All levels describe the maturity in the development of a technology, from the idea to the implementation of the product in the market.

It is worth adding that the TRL scale uses a linear approach, which was usual in the early 1970s. The essential object of development is a component that is improved and integrated into a product. The possibility of delays in maturity as a critical feature of R\&D activities was first incorporated through the 'chain linked model'. In contrast to the implicit linear logic of the TRL scale, these interactive models show that research is needed even at the higher TRL levels, i.e. an increase in maturity also requires further research. Thus, a technology in the pilot production stage can be thrown back temporarily to the technological feasibility stage, as defects in the product design emerge as result of problems in production. Despite having its defects, the TRL scale continues to be adopted by different institutions, including the Department of Defense, the European Space Agency and the European Commission, which uses this concept in Horizon 2020. [15] There are several versions of the TRL scale, according to the entity or industry that uses it and where it is applied. For example, there are specific TRL ranges for the software, biomedical and energy industries, among others.

Grounded on literature $[16,17,18]$ and considering the context of TRL scale, as a first approach, three dimensions have been proposed with a broader scope of analysis, which include the following perspectives:

Scientific Perspective - This perspective is focused on the basic principles of scientific research that transpose into applied research and development and the formulation of practical applications. Development and laboratory testing of technological modules are also implemented at this phase and the basic technological modules are set together to be experienced in a simulated environment.

Technical Perspective - This perspective addresses the prototype experiment in a relevant environment. The system or process demonstration is carried out in an operational situation. The driving force behind this level of development is to assure system engineering and foster management confidence. The goal of this stage is to reduce production risk.

Business Perspective - This phase refers to a complete and qualified system that is ready to be used in a real situation. It is a system that has been approved in operational conditions and is ready to be used in a real scenario. It includes documentation as well as the product, process or service that is launched commercially, and accepted by customers. 


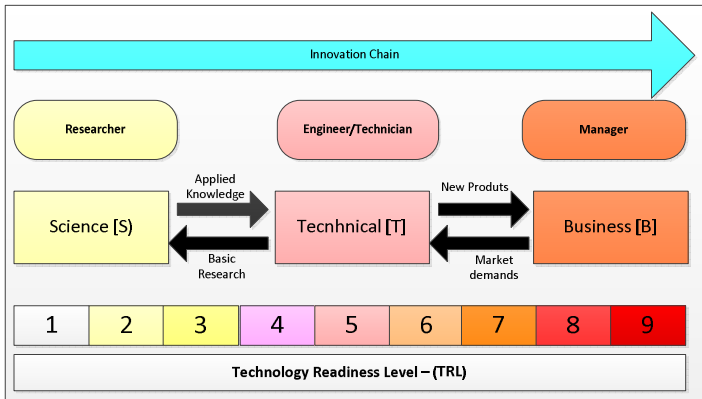

Figure 1 - Innovation chain

The figure 1 shows the relationship between the TRL and our proposal in terms of dimensions, taking into account the different resources and competences required in each stage.

\section{Co-innovation Patterns Model}

In order to understand the role of a co-innovation network in the innovation chain, a model must be developed that supports the analysis of the relationships among enterprises and categorizes the knowledge that may be accessed through the collaborative network.

To do so, we start with the assumption that the contribution of an enterprise to an innovation process is related to the level of relationships that it establishes with other enterprises within a network under a co-innovation perspective. Therefore, as a first approach, using concepts from Social Network Analysis and adopting the model developed by Abreu e Camarinha-Matos [19] these relationships can be modeled using graphs, as showed in Figure 2. 


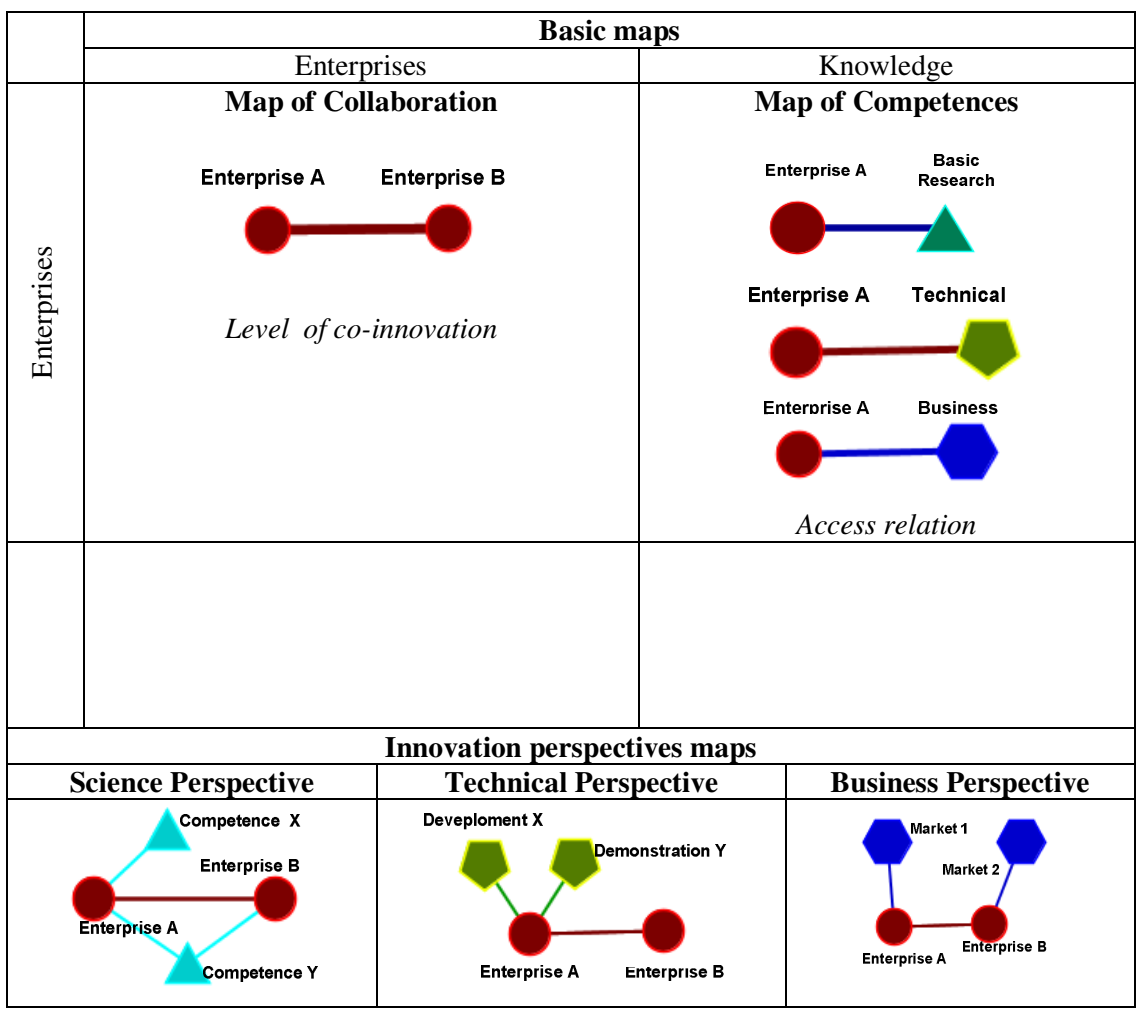

Figure 2 - Simple model to analyze co-innovation in CNs.

However, this simplification implies a partial view and consequently, a limitation of the model. In order to have a complete description of the patterns of innovation it is also important to consider what happens with other enterprises, which are connected with the main enterprise. For instance, other aspects as such as brokerage's roles and value systems should be taken into account. [20]

The proposed model considers basic-maps and Innovation perspectives maps. The Basic maps are:

Map of collaboration - A graph showing the network of formal relationships for the purpose of exchanging knowledge to satisfy a request among enterprises belonging to the co-innovation network. In this map, the link's width represents the level of accessibility for knowledge transfer or level of co-innovation - (LC) between two enterprises in a defined time interval. Taking into account the model developed by Urze and Abreu [21] its value can be given by the following equation: 


$$
\begin{gathered}
L C_{i j}=w_{1} \times T M_{i j}+w_{2} \times C M_{i j}+w_{3} \times+N R_{i j} \\
\sum_{n=1}^{3} w_{n}=1 \text { and } w_{n} \geq 0
\end{gathered}
$$

Where:

$L C_{i j}$ - Level of co-innovation between enterprise $\mathrm{i}$ and enterprise $\mathrm{j}$. It has a value over the interval $[0,3]$ where 0 means null collaboration and 3 means high collaboration. The level of co-innovation is assumed as an abstract quantifiable value based on past benefits in a defined time interval. Furthermore, at this research stage, the level of coinnovation represents only the positive side-effect of the relationships between enterprises in terms of accessibility to the knowledge that may be accessed through the network of contacts, and does not take into account the amount of time, effort and cost spent fostering the relationships.

$T M_{i j}$ - The transfer mechanisms variable focuses on evaluation of distinct ways of "physical" interrelationship that support the process of knowledge transfer between enterprise $i$ and enterprise $\mathrm{j}$ within a network in a defined time interval. It has a value over the interval $[0,3]$ where 0 means null transference of knowledge and 3 means the best use of knowledge transference.

$C M_{i j}$ - The competences management evaluates the principles, policies, and governance rules that may facilitate or constrain the processes of searching for knowledge between enterprise $\mathrm{i}$ and enterprise $\mathrm{j}$ within a network in a defined time interval. It has a value over the interval $[0,3]$, where 3 means a high level of accessibility and dissemination strategy and 0 means a private and confidential strategy.

$N R_{i j}$ - This variable evaluates the nature of the relationships between enterprise $\mathrm{i}$ and enterprise $\mathrm{j}$ within a network in a defined time interval, based on the identification and characterization of the various types of relationships (e.g. subordinate relationships, peer relationships), frequency and intensity of contact that enterprises may have with other enterprises within the co-innovation network. It has a value over the interval $[0$, 3 ], where 0 means a null relationship and 3 means a strong relationship.

The main difficulty is how to calculate each of the three variables mentioned above. Further research and development is required regarding how to collect and record the values without being intrusive in the network enterprises' "life". As a first approach, for instance, the assessment of the nature of the relationships might be determined based on the number and duration of collaborative co-innovation projects implemented over a period of time. The competences management evaluation might be based on the number of new competences that each enterprise acquired over a period of time and the evaluation of the knowledge transfer process might be based on the level of successful past co-innovation collaboration.

On the other hand, if the purpose is to design a simulation model to support the decision-making process, then the values of these components will be parameters of the simulation process. 
Map of Competences - This graph shows the types of competences held by each enterprise and how the competences are shared or possessed by each enterprise. In this case, there are two sets of nodes: enterprises and competences. The nodes are connected by "access " relationships.

Innovation perspectives map - Graph showing how an enterprise may have access to competences held by another enterprise. It results from the aggregation of the map of collaboration and map of competences. Based on this map, it is possible to analyze the potential contribution of each enterprise through a visual representation. Therefore, this map consists of two sets of nodes: enterprises and competences.

Assuming that the competences are classified into classes in accordance with their position in the innovation chain then in this context it becomes possible to analyze the potential contribution of an enterprise according to different perspectives, such as:

- $\quad$ Scientific perspective - related to the ability to generate and produce validated knowledge.

- Technical perspective - related to the ability to develop and demonstrate new products in their final form, under the full range of conditions of the enterprise's operating mission.

- Business perspective - related to the ability to provide new products or services to customers.

Based on this approach it is possible to identify distinct co-innovation networks according to their focus. As illustrated in Figure 3, there are co-innovation networks where the center of interest or activity is mainly on one perspective only - science, technical or business and mixed co-innovation networks.

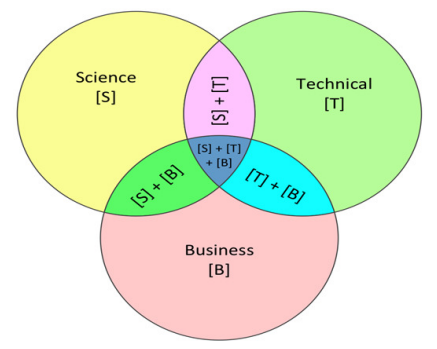

Figure 3 - Types of co-innovation networks

Example 1 - Let us consider a scenario where we have a co-innovation network, which contains eight enterprises, as shown in Figure 4. The purpose of this example is only to show the potential advantages of this model. In the network of collaboration, the level of co-innovation among enterprises $\left(L C_{i j}\right)$, when is not null, is identical for all enterprises. 


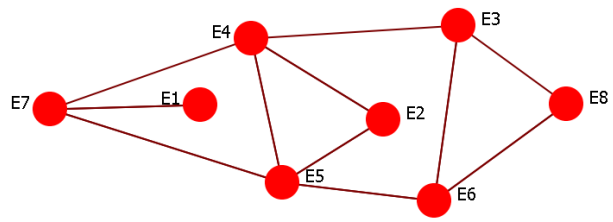

Figure 4 - Map of Collaboration

Assuming that there are three distinct classes of competences (Basic Research, Technical, and Market), as shown in Figure 5. Analyzing the graphs of Competences, it is possible to identify that in terms of basic research (graph 5A) only enterprises E1 and E2 have competences in this area and both enterprises have a competence exclusive to them alone: BR4 in the case of E1 and BR1 in the case of E2. On the other hand, according to the analysis of technical competences (graph 5C), it is possible to verify, for instance, that only enterprise E1 and E7 do not have any technical competences, and apart from the T4 competence, the others are shared by several enterprises.

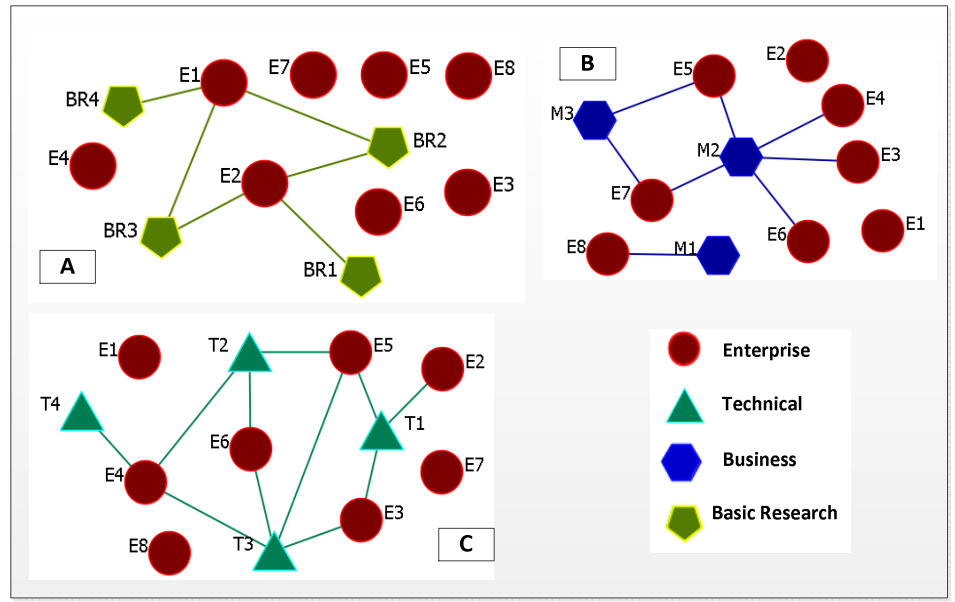

Figure 5 - Example map of enterprises' competences - (A) Basic Research (B) Business and (C) Technical

In order to analyze the innovation potential of a co-innovation network according to different perspectives, the following graphs can be created (Figure 6). From the perspective of basic research (graph 6A), it is possible to verify that both enterprises E4 and E5 might have access to knowledge BR1 (exclusive competence in this network) through the enterprise E2. On the other hand, from the perspective of business competences (graph 6B) enterprise E6 might gain access to market competence M3 through enterprise E5 and might have access to market competence M1 through enterprise E8. From the perspective of technical competences (graph 6C) 
enterprise E4 might have direct access to all available technical competences in this co-innovation network through the enterprise E5, for example.

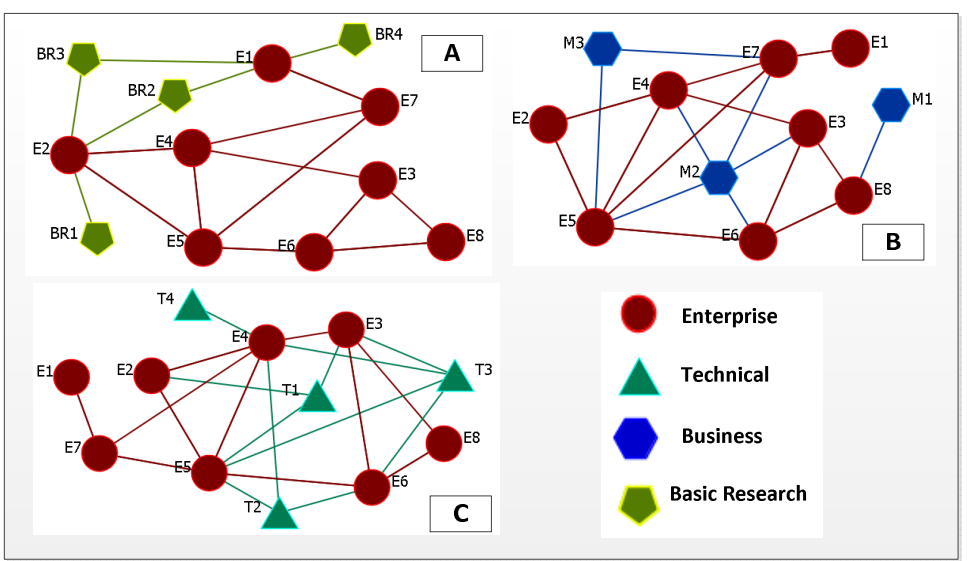

Figure 6 - Example of the potential of co-innovation analysis - (A) Basic Research (B) Business and (C) Technical perspective

\section{Case Study}

\section{Brisa Case Study}

Brisa is the largest operator of highways in Portugal. It is currently responsible for the monitoring and management of a network of eleven highways, representing the main part of the Portuguese road network.

In order to increase its operational efficiency and safeguard its leadership in providing new services to customers, Brisa has developed collaborative relationships with several enterprises and organizations (e.g. research institutions, universities, associations, government entities, start-ups, business angels) that have given rise to the emergence of a long-term co-innovation network.

\section{Methodology}

The research described in this paper is based on the two most relevant co-innovation projects in terms of innovation improvements carried out by the Brisa network.

The methodology used to develop the research comprises two steps. In the first step, the members who had taken part in innovation projects were identified and characterized. In the second step two techniques were applied in order to get empirical data: interviews with key actors and a questionnaire addressed to all members. 
Taking into account the data collected, Table 1 shows the competences involved in the co-innovation projects under study. The number of " $x$ 's" represents the effort made in terms of basic research from the technical perspective.

\begin{tabular}{|c|c|c|c|}
\hline & \multirow[b]{2}{*}{ Competences } & \multicolumn{2}{|c|}{ Level of effort involved in } \\
\hline & & Basic Research & Technical \\
\hline C1 & Computer vision & $x x$ & $x$ \\
\hline C2 & Software Engineering & $x x$ & $x$ \\
\hline C3 & Infrared illumination & $x x$ & $x$ \\
\hline C4 & Automatic pattern recognition & $\mathrm{xxx}$ & $x$ \\
\hline C5 & Toll systems & & $x$ \\
\hline C6 & Information Systems Architecture, & $x x$ & $\mathrm{x}$ \\
\hline C7 & Industrial Design & & $x$ \\
\hline C8 & Modelling of products & & $\mathrm{x}$ \\
\hline c9 & Rapid prototyping & & $x$ \\
\hline C10 & Development of molds & & $x$ \\
\hline C11 & Plastic injection & & $x$ \\
\hline C12 & Functional Tests & & $x$ \\
\hline C13 & Software Development & $x$ & $x$ \\
\hline C14 & Software Architecture & $x$ & $x$ \\
\hline C15 & Project Management & & $d_{\gamma}$ \\
\hline C16 & Functional Analysis & $x$ & $\mathrm{xx}$ \\
\hline C17 & Remote monitoring & $x$ & $x$ \\
\hline C18 & Supplier of equipment for image capture & & $x$ \\
\hline C19 & Electronic Toll Collection (ETC) systems & & $x$ \\
\hline $\mathrm{C} 20$ & Information Systems open to multi-vendor & $x$ & \\
\hline c21 & Automatic vehicle identification systems & $x$ & $\left.\right|^{x}$ \\
\hline C22 & Communication systems between vehicles & $x$ & $x$ \\
\hline C23 & Classification systems of vehicles & $x x$ & $\mathrm{x}$ \\
\hline C24 & Short run production & & $\mathrm{x}$ \\
\hline
\end{tabular}

The graphical visualization of competences provides a tool to evaluate in detail the 'sub-structures' that may be exist in a co-innovation network. Partitions of partners into cliques, i.e. sub-structures of a network in which the partners are more strongly linked to one another than they are to other partners of the co-innovation network can be important to comprehend how the process of innovation flows within the network.

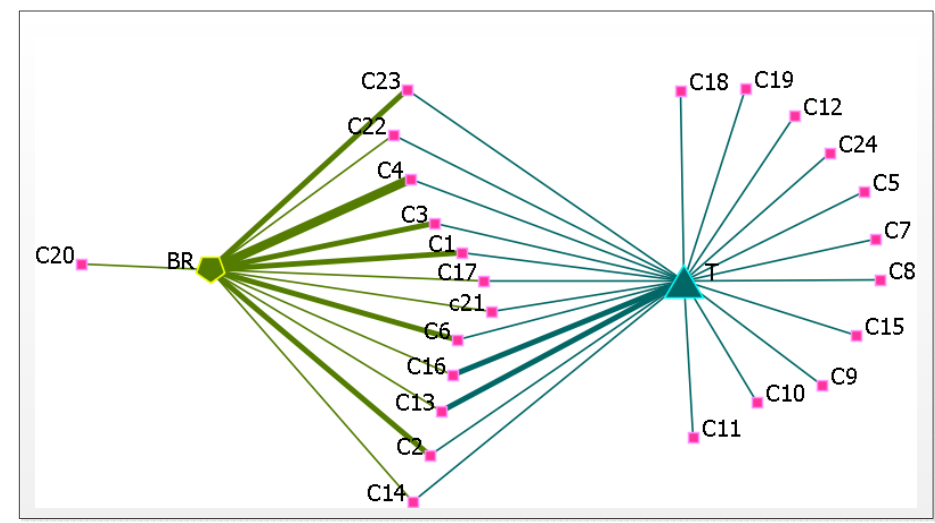

Figure 7 - Level of effort involved in the co-innovation projects under study.

In Figure 7, the node size of Basic Research (BR) and Technical (T) represents the sum of competences used in the co-innovation projects and the node size of the competences is identical because they have no associated metrics. The link's width 
between competences and class of innovation, Basic Research or Technical, represents the level of effort based on each one perspective.

Figure 8 illustrates the distribution of competences by the partners of the coinnovation network.

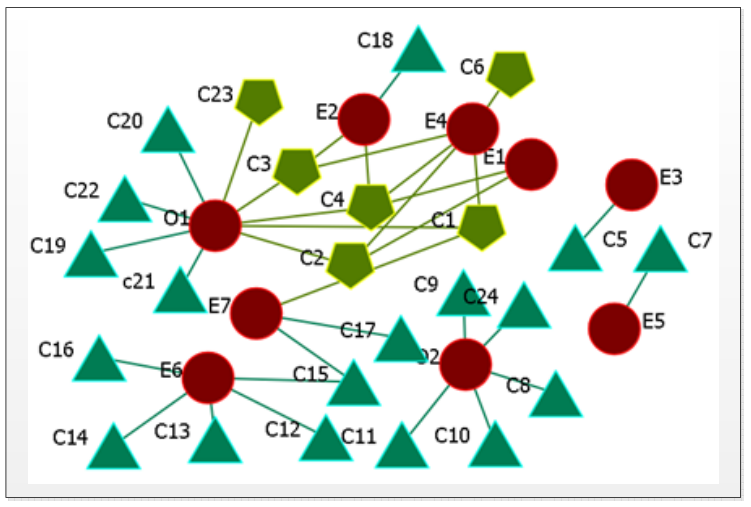

Figure 8 - Competences used by each partner in the co-innovation projects under study.

Hence, the most versatile entities in terms of contribution to basic research and technical perspective are O1, E2 and E7 and $\mathrm{O} 1$ is the one with the greatest number of distinct competences. On the contrary, E5 and E3 are the members that alone contribute with only one competence, $\mathrm{C} 5$ and $\mathrm{C} 7$, to the innovation project. Additionally, some partners are the only ones to hold certain competences, for instance: E6, O1 and $\mathrm{O} 2$ which give them a dominant position within the coinnovation network.

\section{Conclusions}

The development of models to analyze co-innovation networks provides conditions for a broader adoption of the collaborative network paradigm. Furthermore, the development of research activities in this field has contributed to strength the scientific area by promoting new insights to enrich the theoretical debate.

As far as the presented co-innovation networks patterns is concerned, according to the empirical data we can conclude that BIT is a mixed enterprise in the sense that its performance is between the science and technical perspectives. In fact, BIT incorporates the ability to generate and produce validated knowledge and the ability to develop and demonstrate new products.

The application of this mapping to BIT co-innovation network has been a crucial step in terms of showing the use of the proposed approach. The case study gives us an overview about the performance of the different organizations in a collaborative environment, as a strategy to promote innovation flows.

Further research steps are essential regarding the consolidation of a more robust model as well as to strengthen its validation. 


\section{Acknowledgments}

This work was partially supported by BRISA Innovation and Technology (BIT) through a research and development project.

\section{References}

1. Lundvall, B.-Å. (2002), Innovation, growth and social cohesion: The Danish Model, Elgar Publishers.

2. Freeman, C. (1995) The National System of Innovation in historical perspective, Cambridge Journal of Economics, 19, Issue 1, 5-24,.

3. Camarinha-Matos, L.; Afsarmanesh, H.; Galeano, N.; Molina, A. (2009) Collaborative networked organizations - Concepts and practice in manufacturing enterprises, Computers \& Industrial Engineering 57 46-60.

4. Fagerberg, J. (2005), "Innovation: A Guide to the Literature", in The Oxford Handbook of Innovation, Oxford University Press.

5. Grant, R. M. (1996), Toward a Knowledge-Based Theory of the Firm, Strategic Management Journal, Vol. 17, Special Issue: Knowledge and the Firm, 109-122.

6. Marques, A; Abrunhosa (2005) Do Modelo Linear à Abordagem Sistémica - Aspetos teóricos e de política económica, discussion paper, n³3 Centro de Estudos da União Europeia, FE/UC,.

7. Edquist, C. (1997) Systems of Innovation: Technologies, Institutions and Organisations, Printer/Cassel,.

8. Tidd, J. (2006) Innovation Models, Imperial College London, Tanaka Business School,

9. Kline, S.J. and N. Rosenberg (1986) "An Overview of Innovation", in R. Landau and N. Rosenberg (eds) The Positive Sum Strategy: Harnessing Technology for Economic Growth, Washington D.C.: National Academy Press, pp.275-304

10. Caraça, J. Ferreira, J. L.Mendonça, S. A (2007) chain-interactive innovation model for the learning economy: Prelude for a proposal, ISEG, WP 012/2007/DE

11.Godinho, M. M (2013). Inovação em Portugal, Lisboa Fundação Francisco Manuel Santos.

12.Tidd, J., J. Bessant, and K. Pavitt (2005). Managing Innovation: Integrating Technological, Market and Organizational Change, Hong Kong: John Wiley \& Sons, Ltd.

13. Tidd, J. (2006) Innovation Models, Imperial College London, Tanaka Business School,.

14. Mankins, J.C. (2009) A Technology Readiness Assessments: A retrospective, Acta Astronautica, Volume 65, Issues 9-10, November-December, 1216-1223.

15. EARTO, (2014) The TRL Scale as a Research \& Innovation Policy Tool, EARTO Recommendations,.

16. Mankins, J.C. (1995) White Paper, Advanced Concepts Office, Office of Space Access and Technology, NASA,.

17. OCDE, (2005) Oslo Manual: Guidelines for collecting and Interpreting Innovation Data, $3^{\text {rd }}$ Edition.

18. Fagerberg, J. (2005), "Innovation: A Guide to the Literature", in The Oxford Handbook of Innovation, Oxford University Press.

19. Abreu, A., \& Camarinha-Matos, L. M. (2010). Understanding Social Capital in Collaborative Networks. In: Balanced Automation Systems for Future Manufacturing Networks (pp. 109-118). Springer Berlin Heidelberg.

20.Abreu, A., Macedo, P., \& Camarinha-Matos, L. M. (2008). Towards a Methodology to Measure the Alignment of Value Systems in Collaborative Networks. In: Innovation in manufacturing networks (pp. 37-46). Springer US.

21. Urze, P., \& Abreu, A. (2012). Knowledge transfer assessment in a co-innovation network. In Collaborative Networks in the Internet of Services (pp. 605-615). Springer: Heidelberg. 